\title{
Trend Analysis of the Mobile Health COVID-19 Application As A Preventive Strategy in the Era of COVID-19 Pandemic in Surakarta
}

\author{
Aris Widiyanto, Joko Tri Atmojo, Rina Tri Handayani
}

School of Health Sciences Mamba’ul 'Ulum, Surakarta

\section{ABSTRACT}

Background: Digital technology innovation is believed to increase the effectiveness of the health system's response to epidemics. Some of the potential benefits of mobile Health (mHealth) applications for managing the coronavirus 2019 (COVID-19) pandemic have been explored. This study aimed to determine the trend of using mobile health applications during the COVID-19 pandemic in Surakarta, Central Java.

Subjects and Method: This study was descriptive study conducted in Surakarta, Central Java, from February to August 2021. A sample of 184 subjects aged 15 to 64 years was selected in this study. Data were collected using a questionnaire through an online survey. Data were presented in descriptive-analytical form based on the characteristics of gender, age, occupation, and education.

Results: The majority of study subjects were women (84.78\%), with an average age (Mean $=20.61$; $\mathrm{SD}=0.12$ ). As many as 55.98\% had used the COVID-19 mobile health application. $51.45 \%$ were satisfied with the COVID-19 mobile health application service used. As many as $60.19 \%$ of the subjects felt it was faster to get information about COVID-19. $73.78 \%$ of the study subjects reported the mobile health application could improved knowledge about preventing transmission of COVID19. As many as $71.84 \%$ reported that the application could assist in implementing health protocols. Conclusion: The mobile health COVID-19 application accelerates the dissemination of health information, increases knowledge about preventing transmission of COVID-19 and implementation of health protocols.

Keywords: mobile health, COVID-19, application, prevention

\section{Correspondence:}

Aris Widiyanto. School of Health Sciences Mamba'ul 'Ulum Surakarta, Surakarta, Central Java. Email: widiyanto.aris99@gmail.com. Mobile: +628139209095.

\section{Cite this as:}

Widiyanto A, Atmojo JT, Handayani RT (2021). Trend Analysis of the Mobile Health COVID-19 Application As a Preventive Strategy in the Era of COVID-19 Pandemic in Surakarta. J Health Promot Behav. 06(02): 104-111. https://doi.org/10.26911/thejhpb.2021.06.02.03.

(c) (i) (2) Journal of Epidemiology and Public Health is licensed under a Creative Commons Attribution-NonCommercial-ShareAlike 4.0 International License.

\section{BACKGROUND}

Coronavirus Disease 2019 (COVID-19) is an emerging infectious disease that was first identified in China in December 2019. It is caused by infection with severe acute respiratory syndrome coronavirus 2 (SARS-CoV2). On January 30, 2020, the World Health Organization (WHO) declared this disease a Public Health Emergency of International Concern (PHEIC), which then on March 11,
2020, COVID-19 was declared a pandemic. (Gan et al., 2020; WHO, 2020).

Although the SARS-CoV-2 pandemic had a significant impact in terms of quarantine and deaths, the public was becoming more eager to get information about the spread of infection. Their efforts to stay upto-date with the latest information about COVID-19 involve existing technologies such as watching the national bulletin on television or listening to the news on the 
radio. However, most people may not like the idea of waiting for a live broadcast on a fixed schedule. Reading digital news articles and browsing official websites seem to be top choices for tech-savvy individuals. This opens up a golden opportunity for web or mobile medical application developers to create a platform for the public to provide the information they need. With the advancement of software and mobile technology, mobile applications have become an important element in our daily lives (AbdAlrazaq et al., 2020; Chen et al., 2020; Materia, et al., 2020).

The popularity of mobile technology has led to high and increasing ownership of mobile technology, meaning that interventions can be delivered to many people. In 2009, more than two-thirds of the world's population owned a cell phone and 4.2 trillion text messages were sent. In many high-income countries, the number of mobile phone subscriptions exceeds the population. In low-income countries, mobile communications technology is the fastest growing sector of the communications industry with a high geographic coverage (International Telecommunication Union, 2011; Krishna et al., 2009).

The use of mobile computing and communication technologies in healthcare and public health is a rapidly growing area of e-health. There is considerable enthusiasm for mobile-health interventions and great potential to have a beneficial effect on health and healthcare delivery processes, especially in areas with weak infrastructure (Free et al., 2013).

The mHealth app can play a major role in self-management and home care. Several existing studies have explored variations in the use of mobile phones for problems related to health information and consultation. Several studies have also begun to report the results of feedback or responses from users of certain applications, most of which indicate that these technological advances have enabled better health care services to the public (Lang et al., 2008; Costa et al., 2012; Lindberg et al., 2013).

Research on surveys on the use of COVID-19 mobile health applications is still rarely carried out in Indonesia. Therefore, this study aims to determine the trend of using COVID-19 mobile health applications in Surakarta.

\section{SUBJECTS AND METHOD}

\section{Study Design}

This was a descriptive study conducted in Surakarta, Central Java, Indonesia.

\section{Population and Sample}

The study subjects were adults of productive age ( 15 to 64 years). The target population is adults who live in Surakarta.

\section{Study Variable}

The dependent variable is the handling of the COVID-19 pandemic. The independent variable is the COVID-19 mobile health application.

\section{Operational Definition of Variables}

The COVID-19 health mobile application is a health web (mHweb), and medical applications (mHApps) that can be downloaded on the Play store or App Store such as Halodoc, Alodokter, iHealth, MyVitals which are used to access health information and services through devices with internet.

\section{Instrument}

Data collection was carried out using a questionnaire through an online survey.

\section{Data Analysis}

The data will be presented and analyzed in descriptive analytical form based on the characteristics of gender, age, occupation and education.

\section{Research Design}

This research has been approved by the Board of Research Ethics Committee of 
Widiyanto et al./ Mobile Health Application As A Preventive Strategy in the COVID-19 Pandemic

School of Health Sciences Mamba'ul 'Ulum Surakarta, Indonesia.

\section{RESULTS}

1. Sample Characteristics

A total of 184 respondents filled out an online questionnaire containing several

Table 1. Sample Characteristics (dichotomous)

\begin{tabular}{llcc}
\hline Characteristics & Category & Frequency & Percentage \\
\hline Gender & Male & 28 & 15.22 \\
Education & Female & 156 & 84.78 \\
& Senior high school & 5 & 2.7 \\
Occupation & Diploma/bachelor & 180 & 97.3 \\
& Uni student/student & 168 & 91.30 \\
& Health personnel & 3 & 1.63 \\
& Education staff & 1 & 0.54 \\
& Entrepreneur & 3 & 1.63 \\
& Private employee & 9 & 4.89 \\
\hline
\end{tabular}

Table 2. Sample Characteristics (Continous)

\begin{tabular}{ccccc}
\hline Variable & Mean & SD & Min. & Max. \\
\hline Age (year) & 20.61 & 0.12 & 18 & 27 \\
\hline
\end{tabular}

2. Analysis of Trends in the Use of Mobile Health COVID-19 Applications

Of the total 184 respondents, $55.98 \%$ have used the COVID-19 mobile health application. $40.22 \%$ of respondents received infor- questions about the COVID-19 mobile health application. The demographic characteristics of the sample of respondents consist of gender, age, education and occupation (Table 1).

Table 3. List of questions and the number of answers on the questionnaire

\begin{tabular}{clcc}
\hline No & \multicolumn{1}{c}{ List of Question } & Frequency & Percentage \\
\hline 1 & Have you ever used the COVID-19 health & & \\
mobile application? & 103 & 55.98 \\
& • Yes & 81 & 44.02 \\
• No & & \\
& How did you find out about the COVID-19 & & \\
& mobile health application? & & 31.52 \\
& - Advertising services & 58 & 4.35 \\
& - Television & 8 & 40.22 \\
& - Friends, family & 74 & 23.91 \\
\hline
\end{tabular}

Based on the survey results, respondents who answered that they had used the Mobile Health COVID-19 application were 103 respondents, with 16 male respondents and 87 female respondents. Ages ranged mation about the COVID-19 mobile health application from friends or family, $31.52 \%$ from advertising services, $4.35 \%$ from television, and $23.91 \%$ from others consisting of social media, and the workplace (Table 3).

45

from 18-23 years and consisted of high school graduates amounting to 99 respondents and Diploma/Bachelor graduates amounting to 4 respondents. From 103 respondents, 5 respondents work as private 
employees, 94 respondents work as students, 2 respondents work as health work- ers, 1 respondent is an entrepreneur, and 1 respondent works as an educator (Table 4).

Table 4. Trends in the use of Mobile Health COVID-19 based on the characteristics of the study sample

\begin{tabular}{clcc}
\hline No & \multicolumn{1}{c}{ Characteristics } & Frequency & Percentage \\
\hline 1. & Gender & 16 & 15.53 \\
& Male & 87 & 84.47 \\
2. & Age & & \\
& 18-23 & 103 & 100 \\
$3 . \quad$ Education & & \\
& SHS & 99 & 96.1 \\
Diploma/ bachelor & 4 & 3.9 \\
Occupation & & 4.8 \\
& Private Employee & 5 & 91.3 \\
& Univ student/student & 94 & 1.9 \\
& Health Personnel & 2 & 1 \\
& Staff Academic & 1 & 1 \\
& Entrepreneur & 1 & \\
\hline
\end{tabular}

Table 5. List of questions and the number of answers on the questionnaire for respondents who have used the Health COVID-19 mobile application

\begin{tabular}{|c|c|c|c|}
\hline No & Question & n (\%) & Percentage \\
\hline \multirow[t]{3}{*}{1.} & $\begin{array}{l}\text { Are you satisfied with the COVID-19 mobile health application } \\
\text { that you are using? }\end{array}$ & & \\
\hline & - Yes & 53 & 51.45 \\
\hline & - $\mathrm{No}$ & 50 & 48.54 \\
\hline \multirow[t]{3}{*}{2.} & $\begin{array}{l}\text { Do you use the COVID-19 health mobile application to get health } \\
\text { information more quickly, especially about COVID-19? }\end{array}$ & & \\
\hline & - Yes & 62 & 60.19 \\
\hline & - $\mathrm{No}$ & 41 & 39.81 \\
\hline \multirow[t]{3}{*}{$3 \cdot$} & $\begin{array}{l}\text { Does the COVID-19 health mobile application help in } \\
\text { implementing health protocols? }\end{array}$ & & \\
\hline & - Yes & 74 & 71.84 \\
\hline & - $\mathrm{No}$ & 29 & 28.15 \\
\hline \multirow[t]{3}{*}{4.} & $\begin{array}{l}\text { Can the COVID-19 health mobile application increase } \\
\text { knowledge about preventing the spread of COVID-19? }\end{array}$ & & \\
\hline & - Yes & 76 & 73.78 \\
\hline & - No & 27 & 26.12 \\
\hline \multirow[t]{3}{*}{5.} & $\begin{array}{l}\text { Do you think that the COVID-19 mobile health application } \\
\text { should always be developed? }\end{array}$ & & \\
\hline & - Yes & 87 & 84.46 \\
\hline & - $\mathrm{No}$ & 16 & 15.53 \\
\hline
\end{tabular}

Of the 103 respondents who have used the COVID-19 mobile health application, 53 respondents said they were satisfied with the application used, while 50 respondents said otherwise. 62 respondents claimed to get health information faster when using the COVID-19 mobile health application, while 41 respondents said otherwise. A total of 74 respondents answered "yes" to the question "does the COVID-19 mobile health application help in the implementation of health protocols?", 
while 29 respondents answered "no". 76 respondents answered "yes" to the question "Can the COVID-19 mobile health application increase knowledge about preventing the spread of COVID-19?", while 27 respondents answered "no". On the question of opinion, namely "Do you think that the COVID-19 mobile health application should always be developed?", 87 respondents answered "yes" and 16 respondents answered "no" (Table 5).

\section{DISCUSSION}

Based on the results of survey data collection that has been carried out on a research sample of 184 respondents, half of them have used the mHealth COVID-19 application. This phenomenon is in line with the statement that mHealth, which promotes the use of wireless technology in healthcare, is one of the fastest growing fields in electronic health (eHealth). Mobile technology is mobile and popular, so nowadays, almost everyone carries their cell phone with them wherever they go. This allows temporal synchronization of the delivery of interventions that claim people's attention when an intervention or information is relevant to their respective situations and conditions (Free et al., 2013).

The majority of respondents in this study are high school graduates and work as students. This is in line with data by Madden et al., (2013) and Madden et al., (2013) that young people are early adopters of new consumer technologies, such as smartphones and applications. Smartphone ownership among young people is indeed on the rise, from $23 \%$ in 2011 to $37 \%$ in 2012 in the United States, with equal distribution across ethnicities and family incomes. In addition, $58 \%$ of all US youth aged 12 to 17 reported having downloaded an app compared to $34 \%$ of adults.
The use of health applications certainly helps the public in obtaining health information, especially during the COVID-19 pandemic. This is in line with the statement that the use of mobile devices allows for intervention or interaction with individuals in the context of their daily life moments, which is a form of intervention called ecological momentary intervention (EMI). The most reliable method to use in investigating emotions in the real world is to contact people who are doing their daily activities and ask them to report their thoughts, feelings, and actions at that moment (Killingsworth and Gilbert, 2010).

The use of mHealth in the community can also help in implementing health protocols and increase knowledge about preventing transmission or transmission of the COVID-19 virus. There are several policies that have been implemented by each government in the world since the COVID19 pandemic began. According to Han et al., (2020) and Roy \& Ramadoss (2021) worldwide, many countries have adopted different policies to implement classic health care and safety management measures, such as the use of face masks, implementing social distancing), this was all done to curb the spread of COVID-19. The most common national-level health crisis management strategies include imposing lockdowns, bans on out-of-town travel, isolation or quarantine of confirmed positive patients and close contact tracing of positive patients, and bans on gatherings and public transportation.

The development of a COVID-19 mobile health tool (mHealth) to statistically track the progress of COVID-19, monitor potential COVID-19 symptoms, and reduce the social and mental health impact of the COVID-19 pandemic that emerged at the same time as the pandemic (Menni et al., 2020; O'Dowd, 2020). Several COVID-19 
applications that have been developed for public health surveillance provide up-todate statistical information, including the number of new cases, hospitalizations, and confirmed deaths (Menni et al., 2020; O'Dowd, 2020; Soriano et al., 2020). Among applications that enable real-time monitoring of symptoms, trackers and telemedicine systems also help explain the frequency of symptoms associated with COVID-19, enabling patients and healthcare providers to respond early to symptom development (Menni et al., 2020; Timmers et al., 2020; Xu et al., 2020; Yap and Xie, 2020). Reviews of contact tracing applications have highlighted their effectiveness in improving reporting of new cases, management and follow-up of COVID-19 cases, and education on transmission prevention behaviors (Altmann et al., 2020; Echeverría et al., 2020; Jonker et al., 2020; Sun et al., 2020; Walrave et al., 2020; Yasaka et al., 2020).

In addition to the classical policies as described above, the government also needs to highlight or pay attention to, and regulate the use of information traffic in cyberspace, this is considered important because according to Kataki et al., (2021) and Khadse et al., (2020) there are several other factors that we should focus on. For example, the imposition of a lockdown or quarantine policy has drastically improved the habit of shopping for food and equipment online. With the increase in home delivery of food, groceries and other products, proper sanitation protocols and minimal contact with delivery people must be strictly regulated by delivery and transportation systems to minimize the risk of further spreading the virus. The Centers for Disease Control and Prevention (CDC) has established appropriate guidelines to minimize these risks.
The conclusion of this study is that the use of the COVID-19 mobile health application can assist the public in obtaining health information, especially about COVID-19 during quarantine implementation, increasing knowledge about preventing COVID-19 transmission, and implementing health protocols.

\section{FINANCIAL AND SPONSORSHIP}

This research was conducted using the Research Grant Fund for Beginner Lecturers of the Ministry of Research and Technology/National Innovation Research Agency for Fiscal Year 2021.

\section{ACKNOWLEDGMENT}

I would like to say thank you to the participants and Mamba'ul 'Ulum School of Health Sciences.

\section{CONFLICT OF INTEREST}

There is no conflict of interest in this study.

\section{REFERENCES}

Abd-Alrazaq A, Alhuwail D, Househ M, Hamdi M, Shah Z (2020). Top concerns of tweeters during the COVID19 Pandemic: Infoveillance Study. J Med Internet Res. 22 (4): e19016. doi: 10.2196/19016.

Altmann S, Milson L, Zillessen H, Blasone R, Gerdon F, Bach R, Kreuter F, et al. (2020). Acceptability of App-Based Contact Tracing for COVID-19: CrossCountry Survey Study. JMIR Mhealth Uhealth. 8(8): e19857. doi: 10.2196/19857.

Chen C, Jyan H, Chien S, Jen H, Hsu C, Lee $\mathrm{P}$, Lee $\mathrm{C}$, et al. (2020). Containing COVID-19 among 627,386 persons in contact with the Diamond Princess Cruise ship passengers who disembarked in Taiwan: Big Data Analytics. J Med Internet Res. 22 (5): 
Widiyanto et al./ Mobile Health Application As A Preventive Strategy in the COVID-19 Pandemic

e19540. doi: 10.2196/19540.

Costa Â, Novais P, Corchado JM, Neves J (2011). Increased performance and better patient attendance in an hospital with the use of smart agendas. Log J IGPL. 20 (4): 689-698. doi: 10.1093/jigpal/jzro21.

Echeverría P, Bergas MAM, Puig J, Isnard M, Massot M, Vedia C, Peiro R, et al. (2020). COVIDApp as an innovative strategy for the management and follow-up of COVID-19 cases in longterm care facilities in Catalonia: Implementation Study. JMIR Public Health Surveill. 6(3): e21163. doi: 10.2196/21163.

Free C, Phillips G, Watson L, Galli L, Felix L, Edwards P, Patel V, et al. (2013). The effectiveness of mobile-health technologies to improve health care service delivery processes: a systematic review and meta-analysis. PLoS Med. 10 (1): e1001363. doi: 10.1371/journal.pmed.1001363.

Gan WH, Lim JW, Koh D (2020). Preventing Intra-hospital Infection and Transmission of Coronavirus Disease 2019 in Health-care Workers. Saf Health Work. 11(2): 241-243. doi: 10.1016/j.shaw.2020.03.001.

Han E, Tan MMJ, Turk E, Sridhar D, Leung GM, Shibuya K, Asgari N, et al. (2020). Lessons learnt from easing COVID-19 restrictions: an analysis of countries and regions in Asia Pacific and Europe. Lancet. 396 (10261): 1525-1534. doi: 10.1016/So140-6736(20)32007-9.

International Telecommunication Union (2011). The world in 2011: ICT facts and figures. ITU.

Jonker M, Bekker-Grob ED, Veldwijk J, Goosens L, Bour S, Molken MR (2020). COVID-19 contact tracing apps: Predicted uptake in the Nether- lands based on a discrete choice experiment. JMIR Mhealth Uhealth. 8 (10): e20741. doi: 10.2196/20741.

Kataki S, Chatterjee S, Vairale MG, Sharma S, Dwivedi SK (2021). Concerns and strategies for wastewater treatment during COVID-19 pandemic to stop plausible transmission. Resour Conserv Recycl. 164: 105-156. doi: 10.1016/j.resconrec.2020.105156

Khadse PA, Gowda GS, Ganjekar S, Desai G, Murthy P (2020). Mental Health Impact of COVID-19 on Police Personnel in India. Indian $\mathrm{J}$ Psychol Med. 42(6): 580-582. doi: 10.1177/0253717620963345.

Killingsworth MA, Gilbert DT (2010). A Wandering Mind is an Unhappy Mind. 330 (6006): 932. doi: 10.1126/science.1192439.

Krishna S, Boren SA, Balas EA (2009). Healthcare via cell phones: a systematic review. Telemed J E Health. 15 (3): 231-40. doi: 10.1089/tmj.2008.0099.

Lang A, Edwards N, Fleiszer A (2007). Safety in home care: a broadened perspective of patient safety. Int $\mathrm{J}$ Qual Health Care. 20 (2): 130-5. doi: 10.1093/intqhc/mzmo68.

Lindberg B, Nilsson C, Zotterman D, Söderberg S, Skär L (2013). Using information and communication technology in home care for communication between patients, family members, and healthcare professionals: A systematic review. Int $\mathrm{J}$ Telemed Appl. 461829. doi: 10.1155/2013/461829.

Madden M, Lenhart A, Cortesi SGU (2013) Teens and Mobile Apps Privacy., Washington, DC: Pew Internet \& American Life Project. Available at: http://www.pewinternet.org/2013/o8 /22/teens-and-mobile-apps-privacy/.

Madden M, Lenhart A, Duggan M, Cortesi 
Widiyanto et al./ Mobile Health Application As A Preventive Strategy in the COVID-19 Pandemic

SGU (2013) Teens and Technology. Available at: http://www.pewinternet.org/2013/o3/13/teens-and-technology-2013.

Materia FT, Faasse K, Smyth JM (2020). Understanding and Preventing Health Concerns About Emerging Mobile Health Technologies. JMIR Mhealth Uhealth. 8 (5): e14375. doi: 10.2196$/ 14375$.

Menni C, Valdes AM, Freidin MB, Sudre CH, Nguyen LH, Drew DA, Ganesh S, et al. (2020). Real-time tracking of self-reported symptoms to predict potential COVID-19. 26(7): 1037-1040. doi: 10.1038/s41591-020-0916-2.

O'Dowd A (2020). Covid-19: App to track close contacts is launched in England and Wales. BMJ. 370: m3751. doi: 10.1136/bmj.m3751.

Roy S, Ramadoss A (2021). Updated insight into COVID-19 disease and health management to combat the pandemic. 3-39. doi: 10.1016/B978-0-323-85780-2.00017-2.

Soriano JB, Fernandez E, Astora AD, Lliano LAPD, Fernandez-Villar A, CarnicerPont D, Alcazar-Navarrete B, et al. (2020). Hospital Epidemics Tracker (HEpiTracker): Description and pilot study of a mobile app to track COVID-19 in hospital workers. JMIR Public Health Surveill. 6 (3): e21653. doi: 10.2196/21653.

Sun S, Folarin AA, Ranjan Y, Rashid Z, Conde P, Stewart C, Cummins N, et al. (2020). Using smartphones and wearable devices to monitor behavioral changes during COVID-19. J
Med Internet Res. 22(9):e19992. doi: 10.2196/19992.

Timmers T, Janssen L, Stohr J, Murk JL, Berrevoets MAH (2020). Using eHealth to Support COVID-19 Education, Self-Assessment, and Symptom Monitoring in the Netherlands: Observational Study. JMIR Mhealth Uhealth. 8(6):e19822. doi: 10.2196/19822.

Walrave M, Waeterloos C, Ponnet K (2020). Adoption of a Contact Tracing App for Containing COVID-19: A Health Belief Model Approach. JMIR Public Health Surveill. 6 (3): e20572. doi: 10.2196/20572.

WHO (2020). WHO launches campaign against misinformation on coronavirus, The Straits Times.

Xu H, Huang S, Qiu C, Liu S, Deng J, Jiao B, Tan X, et al. (2020). Monitoring and Management of Home-Quarantined Patients With COVID-19 Using a WeChat-Based Telemedicine System: Retrospective Cohort Study. J Med Internet Res. 22(7): e19514. doi: 10.2196/19514.

Yap KY, Xie Q (2020). Personalizing symptom monitoring and contact tracing efforts through a COVID-19 web-app. Infect Dis Poverty. 9(1): 93. doi: 10.1186/s40249-020-00711-5.

Yasaka TM, Lehrich BM, Sahyouni R (2020). Peer-to-Peer Contact Tracing: Development of a Privacy-Preserving Smartphone App. JMIR Mhealth Uhealth. 8(4): e18936. doi: 10.2196/18936. 